\title{
Powder cloud eruptions-Where is the air reservoir and blow-out motor in the Rankine half-body? Comment on "Role of pore pressure gradients in sustaining frontal particle entrainment in eruption currents: The case of powder snow avalanches" by M. Y. Louge et al.
}

\author{
Perry Bartelt ${ }^{1}$ and Othmar Buser ${ }^{1}$ \\ Received 6 January 2012; accepted 12 January 2012; published 27 April 2012.
}

Citation: Bartelt, P., and O. Buser (2012), Powder cloud eruptions-Where is the air reservoir and blow-out motor in the Rankine half-body? Comment on "Role of pore pressure gradients in sustaining frontal particle entrainment in eruption currents: The case of powder snow avalanches" by M. Y. Louge et al., J. Geophys. Res., 117, F02015, doi:10.1029/2012JF002333.

[1] In the recent paper "Role of pore pressure gradients in sustaining frontal particle entrainment in eruption currents: The case of powder snow avalanches," Louge et al. [2011] propose that powder snow avalanches belong to a special type of geophysical flow, an "eruption current." These gravity currents are characterized by massive blow-out of ice particles, forming the cloud of a powder avalanche. The authors show that the rise in pressure at the head followed by the pressure drop behind the front produces body forces which can overcome the cohesion of the incumbent snow cover, causing a "blow out" and therefore the distinctive eruptive form of a powder avalanche. This evolution in pressure can be modeled with potential flow theory [Turnbull and McElwaine, 2010] and has been compared to one avalanche event at the Swiss Vallée de la Sionne test site. It is suggested that the generated interstitial fluid pressures within the fluidized snow cover can enhance the mobility of these snow flows as they are running over an erodible porous substrate.

[2] Our comment to the authors centers on the source of the eruptions, which requires a reservoir of air besides the snow particles. The authors apply potential flow theory using a Rankine half-body to derive the velocity and pressure field surrounding the avalanche head. In potential flow theory the flow field around a rigid body is "created" by the superposition of a parallel flow field with a fictional point source. A source involves continual creation of fluid and therefore an "infinite" reservoir of air. The strength of the source defines the height of the separatrix (the height of the powder avalanche) and the distance between the stagnation point (the front of avalanche) and the source.

[3] Our problem is that the powder cloud is certainly not a solid rigid body; that is, the point source is no longer a

\footnotetext{
${ }^{1}$ WSL Institute for Snow and Avalanche Research SLF, Davos, Switzerland.

Published in 2012 by the American Geophysical Union.
}

simple and convenient mathematical construct devoid of any physical meaning. In an avalanche, the source represents a true physical source of air that is required to form the powder cloud. Particles are mixed with the air, but, as pointed out by Louge et al., the Stokes number of the particles is small and therefore we can consider the particles as reliable tracers for the air movement during the cloud's formation. It is this unnamed source of air that gives a powder avalanche its eruptive form and finally allows us to apply potential flow theory to calculate the pressure field around the front of the avalanche. This fundamental point is not clearly worked out in the paper of Louge et al. and leads to some confusion with important consequences. For example, what is the sequence of events envisioned by the authors? Let us say that at some point during the avalanche flow, the avalanche erupts, forming a plume (Figure 1). The plume contains particles (from somewhere in the avalanche, perhaps the snow cover) which allows us to trace the height of the ejaculated air. Is the separatrix of the Rankine half-body defined at the beginning or end of this process? In their estimation of the powder cloud density (equation 16), Louge et al. use the entire ice mass from the snow cover distributed over the height of the Rankine half-body, indicating that the separatrix is defined at the end of the eruption. However, not only must the ice particles be distributed, but also the air inside this volume. Increasing the volume would create a drop in air pressure because there can be no flow through the separatrix. As the tracers indicate, the eruptions have a definite mass flow and are not a pressure wave. This is an important problem of cause and effect. Does the potential flow field cause the eruption (as the authors seem to indicate) or does the eruption produce the potential flow field (as we believe)? We have no doubt that the calculations of Louge et al. are correct; that the generated pressures can fluidize a nearly cohesionless snow cover, but what is the pressure source initiating and maintaining the flow of air?

[4] Potential flow theory indicates that the pressure source is external, caused by the velocity field surrounding the 
"rigid" powder cloud. The source of air mass must be internal since the air cannot flow through the impermeable separatrix of potential flow theory. Perhaps there is an internal pressure source that creates the blow-out, the powder cloud and thus the potential field. This is an important question because an internal source might be more powerful than the pressures generated by potential flow theory, providing us with even more energy to fluidize and erode the snow cover. An internal source would also allow us to take the air needed to dilute the eruptive plumes (Figure 1) by mixing with the ambient air, similar to jet theory [Davidson, 2004]. It is essential to answer this question before powder snow avalanche models can be advanced.

[5] Finally, to support their theory, Louge et al. use the Vallée de la Sionne avalanche 628 of 19 January 2004 as reference event (Figure 1). A significant feature of this avalanche is that the deposits consisted of millions of dense, well-rounded snow granules (Figure 2). This feature of the deposits was the primary motivation to develop a granular flowing avalanche model based on shallow water theory

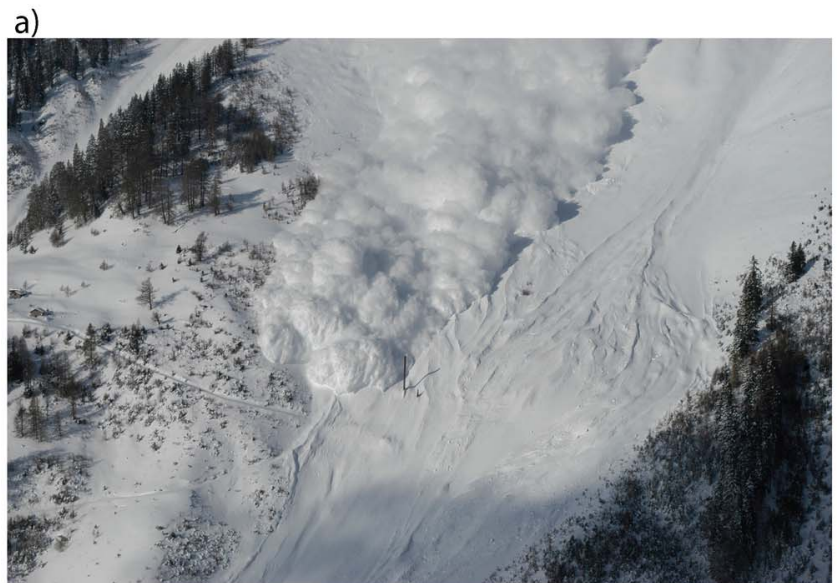

b)

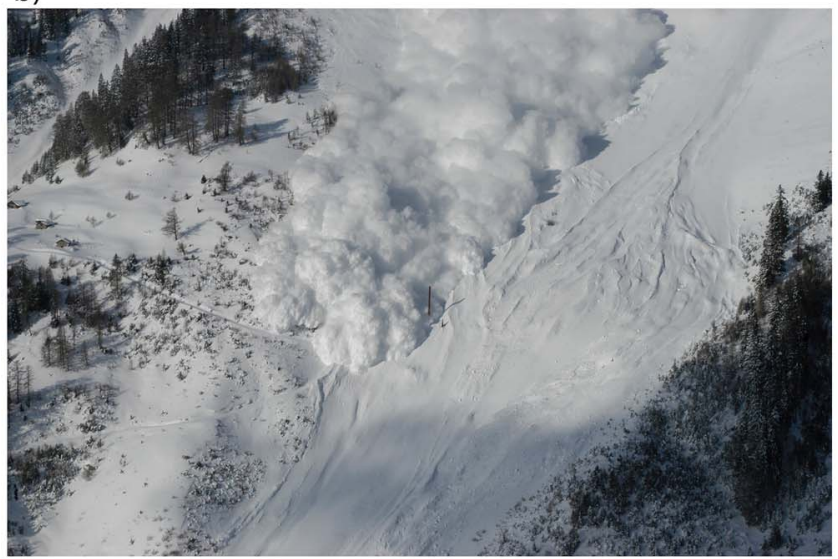

Figure 1. The powder cloud eruptions of Vallée de la Sionne avalanche 628 (19 January 2004). The avalanche is passing the $20 \mathrm{~m}$ high measurement pylon which is visible at the very center of the picture. The ice particles trace the location of the blow-out plumes. The pictures are separated by one second.

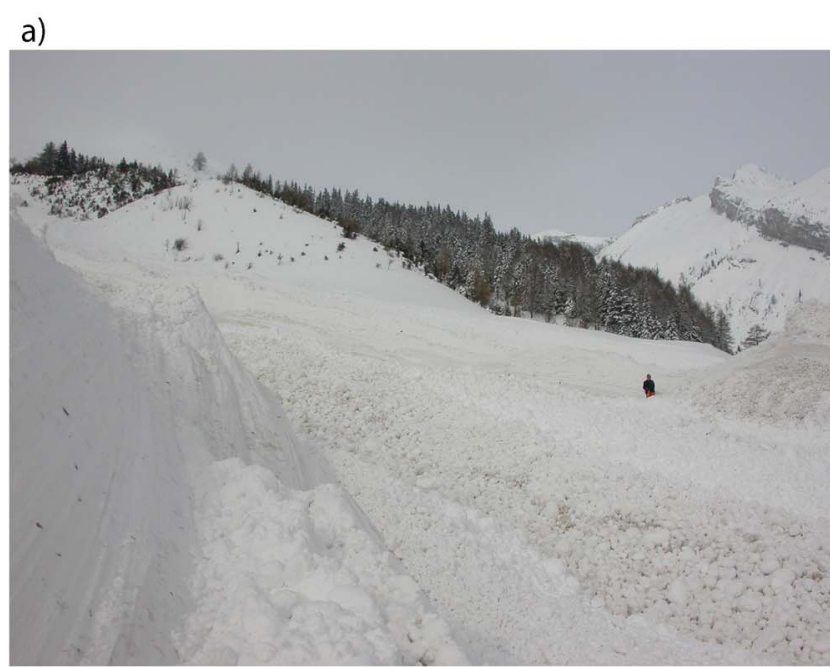

b)

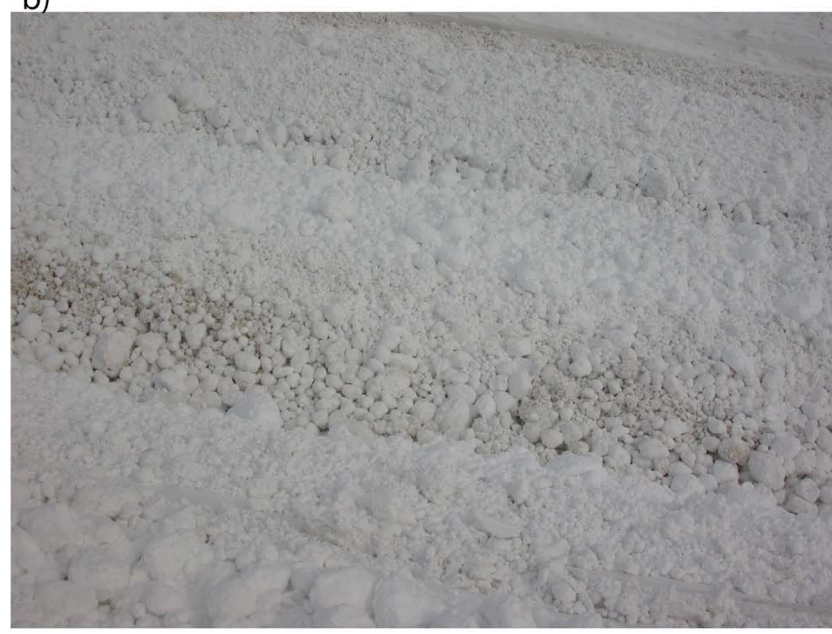

Figure 2. The deposits of Vallée de la Sionne avalanche 628 (19 January 2004). The flowing avalanche consisted of hard, well-rounded granules of various sizes. Avalanche 628 was not a pure powder avalanche.

[Christen et al., 2010; Bartelt et al., 2012]. Avalanche 628 was clearly not a pure powder avalanche, but consisted of a dense granular flowing avalanche, which must produce the powder cloud. We now wonder if the pressure source for the eruptions, the air blow-out, is linked to flow density variations within the granular flow at the head of the avalanche. Velocity gradients would forcibly constrict the air volume and create pulse-like eruptions. Density variations in flowing snow avalanches appear to operate at a defined frequency [Buser and Bartelt, 2011]. If so, the dynamics of flowing avalanches and powder snow avalanches are not "dramatically" different as the authors suppose, but intimately linked by the interstitial fluid, namely air.

\section{References}

Bartelt, P. A., Y. Bühler, O. Buser, M. Christen, and L. Meier (2012), Modeling mass dependent flow regime transitions to predict the stopping and depositional behavior of snow avalanches, J. Geophys. Res., 117, F01015, doi:10.1029/2010JF001957. 
Buser, O., and P. Bartelt (2011), Dispersive pressure and density variations in snow avalanches, J. Glaciol., 57, 857-860, doi:10.3189/ 002214311798043870.

Christen, M., J. Kowalski, and P. Bartelt (2010), Numerical simulation of dense snow avalanches in three dimensional terrain, Cold Reg. Sci. Technol., 63, 1-14, doi:10.1016/j.coldregions.2010.04.005.

Davidson, P. A. (2004), Turbulence, Oxford Univ. Press, New York.

Louge, M. Y., C. S. Carroll, and B. Turnbull (2011), Role of pore pressure gradients in sustaining particle entrainment in eruption currents: The case of powder snow avalanches, J. Geophys. Res., 116, F04030, doi:10.1029/ $2011 \mathrm{JF} 002065$.

Turnbull, B., and J. McElwaine (2010), Potential flow models of suspension current air pressure, Ann. Glaciol., 51(54), 113-122, doi:10.3189/ 172756410791386490 .

P. Bartelt and O. Buser, WSL Institute for Snow and Avalanche Research SLF, CH-7260 Davos, Switzerland. (bartelt@slf.ch) 